\title{
Assessment of Runoff Changes under Climate Change Scenarios in the Dam Basin of Ekbatan, Hamedan Iran
}

\section{Nazari P*, Kardavany H, Farajirad P and Abdolreza A}

Department of Geography, Science and Research Branch, Islamic Azad University, Tehran, Iran

*Corresponding author: Nazari P, Department of Geography, Science and Research Branch, Islamic Azad University, Tehran, Iran. Tel: 44865179-82; E-mail: hnpoya@yahoo.com

Received date: Apr 16, 2016; Accepted date: Sep 08, 2016; Published date: Sep 19, 2016

Copyright: () 2016 Nazari P, et al. This is an open-access article distributed under the terms of the Creative Commons Attribution License, which permits unrestricted use, distribution, and reproduction in any medium, provided the original author and source are credited.

\begin{abstract}
In this study, the uncertainty of the effects of climate change on temperature, rainfall and runoff in the watershed done using the output of models MPEH5, HADCM3 and IPCM4 under two scenarios for 2045-2065 period. After performance of LARS-WG model for downscaling of rainfall and temperature variations, the monthly change rainfall and temperature evaluated for the 2065-2045 period relative to 2010-1983 base period. Results showed that all three models based on two scenarios reduce the amount of rainfall and increases in average temperature in the region. The average annual temperature rise according to the scenario $\mathrm{A} 2,2 / 12^{\circ} \mathrm{C}$ and scenario $\mathrm{B} 1,1 / 12^{\circ} \mathrm{C}$. The amount of rainfall decreases for the period 2045-2065 under the scenario A2, -6/1 and the scenario B1, $-1 / 4$ per cent. To study the effects of climate change on monthly runoff regime, production variables was used to the model of rainfall- runoff IHACRES after that runoff was predicted for the period 2065-2045. The results showed that annual river flow reduced under the $A 2$ scenario $-17 / 2$ percent and the B1 scenario $-19 / 4$ per cent. The overall results showed that despite the uncertainty in climate models MPEH5, HADCM3 and IPCM4 under the A2 and B1 in the amount of temperature increase and rainfall decreases and negative effects of these changes on the runoff area.
\end{abstract}

Keywords: Climate change; Runoff; Uncertainty; Hamedan; LARSWG; IHACRES

\section{Introduction}

In recent decades, increasing greenhouse gases, consumption of fossil fuels, especially gas $\mathrm{CO}_{2}$ as a result, an increase in the gas concentration of $280 \mathrm{ppm}$ in 1750 to $380 \mathrm{ppm}$ in 2005. IPCC1 reports indicate that, if current trends continue using these fuels, the concentration of gas before the end of the twenty-first century may reach more than $\mathrm{ppm} 600$. If emissions not reduced, average earth surface temperature 1.1 to $6.4^{\circ} \mathrm{C}$ by 2100 will be reached. Therefore, according to reports IPCC, climate change causes changes in the hydrological regime in recent decades globally [1]. Increased surface temperatures and changes in rainfall patterns are dominant phenomena of climate change which affects almost all other sectors of the water cycle. All models AOGCMs predict increase in global temperature and increased precipitation intensity and its value as a result of increased concentrations of greenhouse gases in this century. Several studies by Hamlet and others in 2007 have been done about the potential impact of climate change on water resources, including the impact on water quantity, hydrology and water demand. Chang and Jung [2] examined annual runoff, seasonal and minimum and maximum values of runoff and uncertainty in the 218 Sub basin Willamette river in Oregon. The results showed that increased in seasonal changes runoff during the winter and decreased during the summer and change in temporal and spatial of runoff in the future. Gaussian studied impact of climate change scenarios on discharge in Indian River basin for the period 2041-2060. Their results indicate that the flow and intensity of floods and droughts is increasing. Perovskite using output of monthly rainfall HadCM3 model, investigated the effect of rainfall changes on runoff in eight regions in the United States. They reported that annual rainfall changes from $9.6 \%$ to 1.6 and runoff from $42.5 \%$ to $14 \%$. By the Senator and others studied, effects of regional climate models based on A2 and A1B scenarios for river basin Kraty in southern Italy. They predicted that in the period 2077-2099 mean temperature increases, between 3.5 to $3.9^{\circ} \mathrm{C}$ while precipitation will decrease $9 \%$ to $12 \%$. This causes reduction annual cumulative snow $28 \%$ to $29 \%$. The amount of subsurface water decrease between - 6.5 to $41.4 \%$ and surface runoff decrease between -52.4 percent to -14.2 percent. Yi et al. [3] used IHACRES model in Australia for the some of basin with an area of 1582 and 517 square kilometers. Its performance was compared with 22 parameters LASCAM model and parameter 8 GSFB model. Absolute error of assessment in daily flow was calculated using IHACRES, $10 \mathrm{~mm}$ per day. However, according to Nash factor, performance has been good, thus model has done excellent. Post to simulate daily flow in watersheds without data relationship established between model parameters and characteristics of watersheds in south eastern Australia and have used to predict daily stream by temperature data, daily rainfall and basin characteristics. Some of these relationships were determined with acceptable accuracy. While others were relatively weak, so the predicted daily flow of current observations showed little difference in quality. Crooke and Little wood 2005 showed that IHACRES model in seven water shed in Wales so CMD edition model has better performance than the previous version for basins larger than 1,000 square kilometers. Anderson for reduced forest cover in order to show the possible impact on river discharge at the lake in the north of the United States, created regression among the factors affecting river flow. But could not gain a regional model for flow routing parameters. Groce used IHACRES for 42,000 square kilometers area in the southern basin in Wales, Australia. They used a version of IHACRES which includes a soil moisture was used and integrated way to the daily data for each subbasin. IHACRES parameters values were estimated using average values for the subbasins with no data from the subbasins of statistics or by local relations. They established relationship between 
the parameter values and percentage of forest cover and watershed area. Results showed that in two subbasin, model performance was not satisfactory due to the lack of meteorological stations but overall performance is suitable for use in runoff. Bovany evaluated the effects of climate change in the two periods 2070-2099 and 2010-2039 under two climate change scenarios A2 and B2 in the river flow Zayandehrood. Their findings indicate that reduced in both periods between 10 and 16 percent in rainfall and increase in average temperatures between 4.6 and $3.2^{\circ} \mathrm{C}$, respectively $\mathrm{A} 2$ and $\mathrm{B} 2$ scenarios. They were using a neural network to simulate rainfall runoff basin, findings show decrease to $5.8 \%$ and increased runoff coefficient of variation up to 3 times in the next period. Zarghami et al. [4] to predict the effects of climate change using outputs HadCM3 and LARS-WG model in Azerbaijan. The results using artificial neural network showed that reducing runoff of rivers. In 2009 Abbaspoor concluded that using CGCM climate model scenarios A1B, B1, A2 for 37 meteorological stations in Iran in the period 2070-2100, rainfall in arid regions decreases and increases in wet areas. Modaresi investigated the impact of climate change on the annual discharge of the river in Gorgan and downscaled outcome of various scenarios of general circulation models ECHAM, GFDL-R30, CGCM2, CSIRO, HadCM and the CCSR. They concluded that Gorgan river discharge decrease in the 50 and 100 -year return periods, 1.83 and 1.33 percent, respectively. The impact of climate change on the basin runoff Gharehsou in the northwestern basin floodplains with respect to uncertainty in hydrological models were studied by Kamal and Bovany 1389. The results determined that reducing runoff for the fall season and it increased in other seasons during the period 2040-2069. Ghorbanizadeh studied the impact of climate change on the distribution of runoff from snowmelt in the basin of Karoon using the scenario of climate model ECHAM4 outputs in the 25-year period from 2000 to 2050 . They found that the maximum flow will be transferred from spring to winter also increase in the basin discharge $10 \%$ in winter but decreases spring and summer. According to studies, we can conclude that the status of surface runoff of rivers affected by climate change in future periods will be some changes compared to the baseline. Over all Temporal and spatial variations in each region are different. So it is essential to study climate changes in different basins separately. Therefore, in this research effort to study the impact of climate change on variables such as, temperature, precipitation and surface runoff Dam Basin, located in Hamedan province in the period 2045-2065 under A2 and B1 emissions scenarios of future greenhouse gas.

\section{Materials and Methods}

\section{Study Area}

A schematic of the study area, along with catchment boundaries and gauging sites, is given in (Figure 1). Dam Basin of Ekbatan with an area of 160 square kilometers located in the center of the Hamedan province $48^{\circ} 41^{\prime}$ and $48^{\circ} 30^{\prime}$ east longitude and $34^{\circ} 36^{\prime}$ and $34^{\circ} 46^{\prime}$ north latitude on the northern slopes of Alvand. Surface soil texture of basin is 13.5 percent light and 55 percent average. About 22.3 percent of the area under cultivation is rainfed and 17.1 percent irrigated and 60.6 percent used for grassland. The maximum and minimum height of basin range between 1970 and 3467 meters and average altitude of basin is 2524 meters. About 26.5 percent of the watershed area have $0-10 \%$ slope, 3.6 percent watershed area has slopes greater than $30 \%$ and $67.3 \%$ of the watershed area also has a slope of between $10 \%$ and $30 \%$. During the period 1983-2009 the total volume of the Dam Basin of Ekbatan is 44.15 million cubic meters per year and average annual discharge 1.4 cubic meters per second. The lowest monthly discharge 0.008 cubic meters per second is in September and highest average monthly discharge 9.4 cubic meters per second in April.

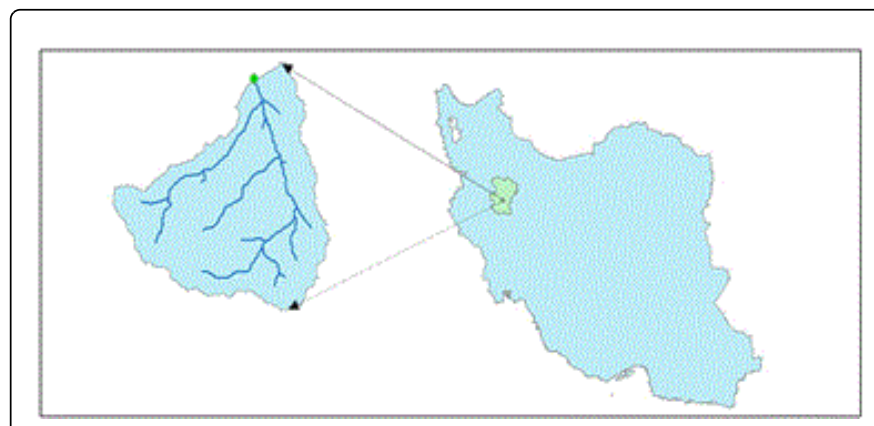

Figure 1: Location map of Dam Basin of Ekbatan basin.

\section{Generation Weather Data Using AOGCM Model}

One of the main uses of stochastic weather generators is in the generation of daily weather data representing scenarios of climate change. Most climate change scenarios are derived from the output of global climate models (GCMs). For assesment of climate change effect on runoff first were simulated, temperature and precipitation parameters for the next decade 2046-2065, using results of model outputs coupled ocean atmosphere (AOGCM) under two emission scenarios. Hydrological studies are often associated with small scale process and basins which scale is much smaller than the scale atmospheric circulation models give us. The GCM models should be downscaled for use in hydrological studies. There are two ways to downscaling data on a local or regional scale using global climate scenarios, include dynamical and statistical methods. In this study to predict climatic parameters, weather generatore, LARS-WG is used to downscaling of general circulation models. Therefore Climatic variables such as daily maximum temperature, minimum and precipitation were produced for study area during period 2065-2045 by three general circulation models MPEH5 'HADCM3 and IPCM4 for scenario A2, B1. Then using simulated daily precipitation and temperature data, the upcoming runoff was assessed using hydrological IHACRES model.

\section{LARS-WG model}

LARS-WG model used for generating synthetic weather data and to simulate meteorological data in one place, present, and future climatic conditions. Data generated on a daily time series suitable for a range of variables, for example, precipitation, minimum and maximum temperatures and radiation (MJ per square meter). The remarkable thing is that the artificial generation of climate data are not tools to predict that can be used to predict weather but they are ability to produce time series data for climate monitoring. The data produced by the Simulation and artificial climate can be done on a local scale in a regional climate change research. In this model, the process of production of artificial weather data is done in three sections: 1-Site Analysis 2-Model verification 3-Production and simulation of climatic variables for the future period. So the implementation of the model include: 1-Observation data 2-Analysis 3-Calibration 4-verification 5Select appropriate General circulation model 6- Select emission scenarios 7-Simulation daily data 8-Analysis Results. 


\section{Rainfall-runoff modelling}

IHACRES is a lumped metric conceptual water balance model developed by Jakeman and Hornberger [5]. IHACRES has been successfully applied to a large number of catchments varying in scale, time step and climate. Originally, IHACRES was developed to model stream flow in humid regions. The first application was realized in two small humid upland catchments in Wales [5]. The first application in semiarid to arid catchments was accomplished by Ye et al. [3] who applied a modified version of IHACRES to three low-yielding ephemeral catchments in western Australia.

The IHACRES model includes a non-linear loss module to estimate the effective rainfall and a linear routing module to model the conversion of the effective rainfall into stream flow using the total unit hydrograph incorporating both quick and slow flow components [5]. The model estimates stream flow from rainfall and temperature inputs calibrated against observed stream flow on a daily basis.

The IHACRES model is a hybrid conceptual-metric model, using the simplicity of the metric model to reduce the parameter uncertainty inherent in hydrological models while at the same time attempting to represent more detail of the internal processes than is typical for a metric model. Figure 2 shows the generic structure of the IHACRES model. It contains a non-linear loss module which converts rainfall into effective rainfall (that portion which eventually reaches the stream prediction point) and a linear module which transfers effective rainfall to stream discharge. Further modules can be added including one that allows recharge to be output. The inclusion of a range of non-linear loss modules within IHACRES increases its flexibility in being used to access the effects of climate and land use change. The linear module routes effective rainfall to stream through any configuration of stores in parallel and/or in series. The configuration of stores is identified from the time series of rainfall and discharge but is typically either one store only, representing ephemeral streams, or two in parallel, allowing base flow or slow flow to be represented as well as quick flow. Only rarely does a more complex configuration than this improve the fit to discharge measurements [5].

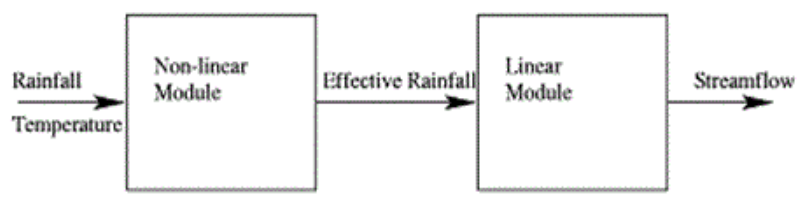

Figure 2: Generic structure of the IHACRES model, showing the conversion of climate time series data to effective rainfall using the Non-linear Module, and the Linear Module converting effective rain fall to stream flow time series.

\section{Results}

\section{Uncertainty of climate change scenarious}

Uncertainty is the absence or lack of information about the situation or the results of a process. Uncertainty cannot be completely removed but its scope will be reduced with further investigation. The greatest uncertainty in climate modelling, which features in all climate downscaling techniques, stems from the unpredictability of future anthropogenic greenhouse gas emissions and their resultant atmospheric concentrations. The IPCC Special Report on Emissions Scenarios [6] discusses several factors that impact on the atmospheric greenhouse gas concentrations projected over the present century: population growth, economic and social development, the development and utilization of carbon-free energy sources and technology and changes to agricultural practices and land use. The four storylines on which the SRES scenarios are based capture just some of the ways in which these driving forces might change [7]. Uncertainty in climate science is a case of 'imperfect knowledge and what Gershon [8] identifies as 'causes of imperfect knowledge are all present. However, due to the complexity of the climate system and the modelling process, the relationships between uncertainty types must also be considered. Uncertainty in the climate system has two main sources. First, there is uncertainty over human action, including uncertainty due to unknown future emission concentrations of greenhouse gases and aerosols. This uncertainty is largely due to unknowable knowledge, and is inherently irreducible [9]. Second, there is uncertainty over how the climate system is likely to respond to our actions. Further research may reduce this uncertainty, but may also uncover previously unknown processes, thereby increasing uncertainty. Additionally, in a complex, non-linear system the existence of unknown states or the occurrence of 'surprise' events is also possible [10].

So in this study changes in rainfall and temperature have been investigated over the period 2045-2065 by three general circulation models MPEH5 'HADCM3 and IPCM4 and scenario A2, B1 with the implementation of the LARS-WG model and finally evaluated uncertainty climate change models and A2, B1scenarious.

\section{Monthly mean precipitations}

The results of the uncertainty of estimates by taking three general circulation models MPEH5 ' HADCM3 and IPCM4 models, A2 and B1 scenario for the period 2045-2065 indicate that there is significant uncertainty in estimating the monthly, quarterly and annually in the basin. Box plot charts used in order to assess the uncertainty. Accordingly, minimum, $25 \%$ or first quartile, median or $50 \%, 75 \%$ or third quartile and maximum calculated then Box charts produced to determine the uncertainty climate models [11-13].

Over the period 2045-2065 the highest and lowest uncertainty of monthly precipitation in the basin under two scenarios occurred in April and October. The results showed that the monthly precipitation changes in future conditions in A2 scenario decreases percent of monthly precipitation $-45.3 \%$ in October $(-10.8 \mathrm{~mm})$ and according to the B1 scenario, decreases -34.5 percent in October $(-8.2 \mathrm{~mm})$.

Due to the high and low monthly precipitation changes, based on A2 scenario percent of monthly precipitation will be changed, - 35 percent in October to 25.4 percent in November (-11.8 to $12.6 \mathrm{~mm}$ ) (Figures 3 and 4). 
Citation: $\quad$ Nazari P, Kardavany H, Farajirad P, Abdolreza A (2016) Assessment of Runoff Changes under Climate Change Scenarios in the Dam

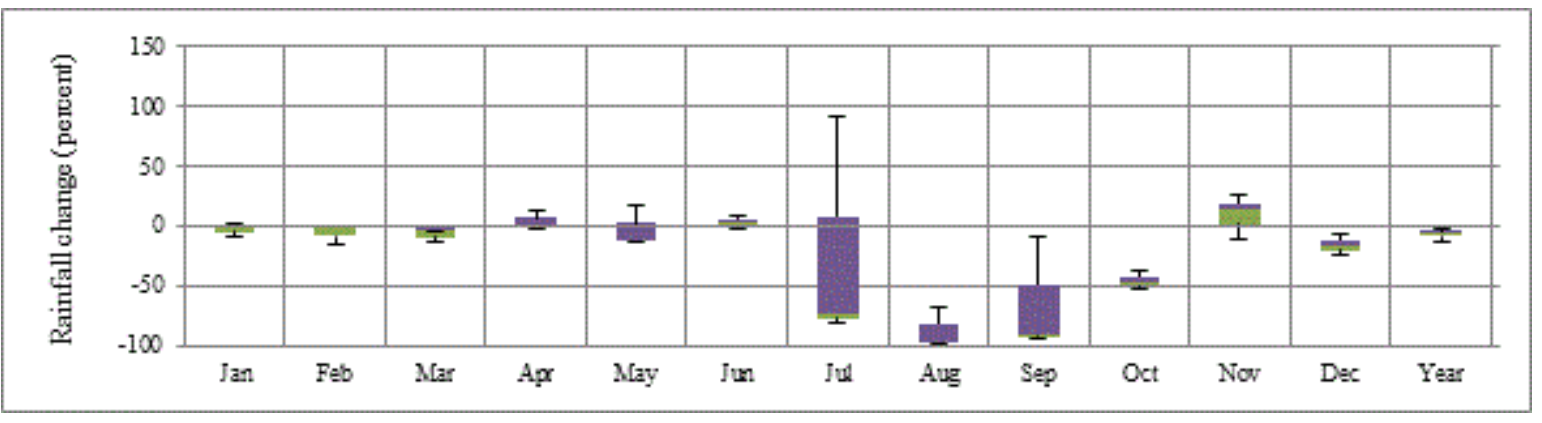

Figure 3: Boxplots showing uncertainty climate models (MPEH5 'HADCM3 and IPCM4) on monthly rain fall Change under the A2 scenarios for the future periods 2045-2065 relative to reference periods 1983-1999.

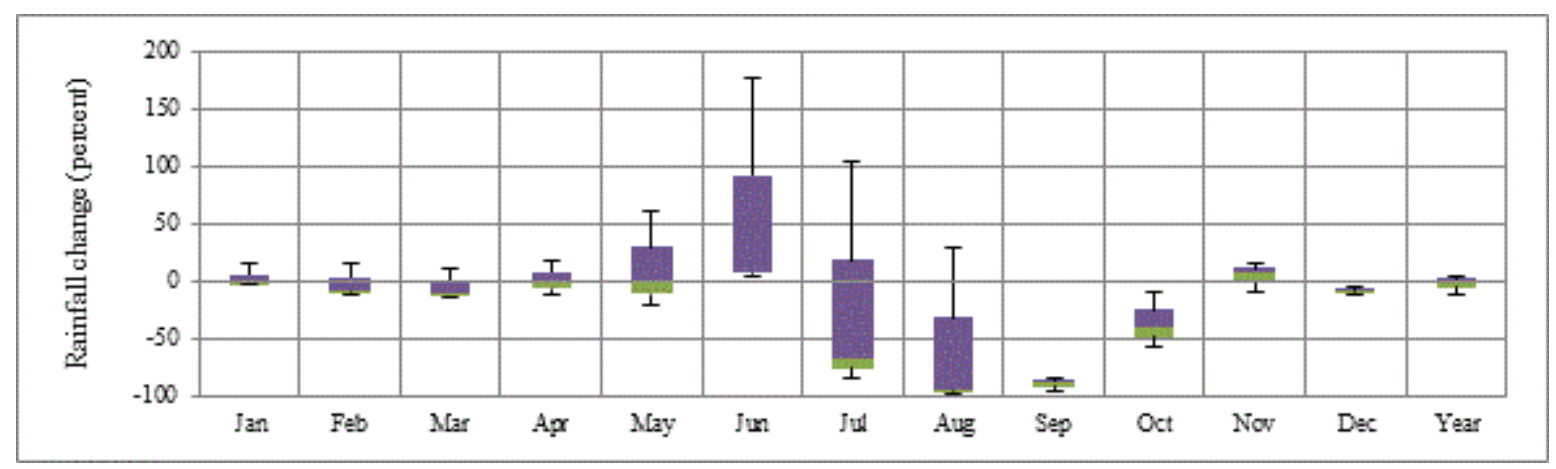

Figure 4: Boxplots showing uncertainty climate models (MPEH5 'HADCM3 and IPCM4) on monthly rain fall Change under the B1 scenarios for the future periods 2045-2065 relative to reference periods 1983-1999.

The maximum and minimum uncertainty seasonal rainfall in the basin during the period 2065-2045, according to two scenarios occurred in the spring and fall. Review on seasonal rainfall results shows that in the worst case future, in A2 scenario percent of seasonal rainfall decreases -11.4 percent in the fall $(-13.1 \mathrm{~mm})$ and the scenario $\mathrm{B} 1,-8.1$ percent in the fall $(-10.4 \mathrm{~mm})$. In this period the amount of monthly rainfall decrease all of the months in the year exception of the months of April, June and November. Also except spring, seasonal rainfall will decrease in other seasons. Annual rainfall will be reduced according to $\mathrm{A} 2$ and $\mathrm{B} 1$, respectively, $-6.1 \%$ and $-1.4 \%$ (Figures $5-7$ ) (Table 1).

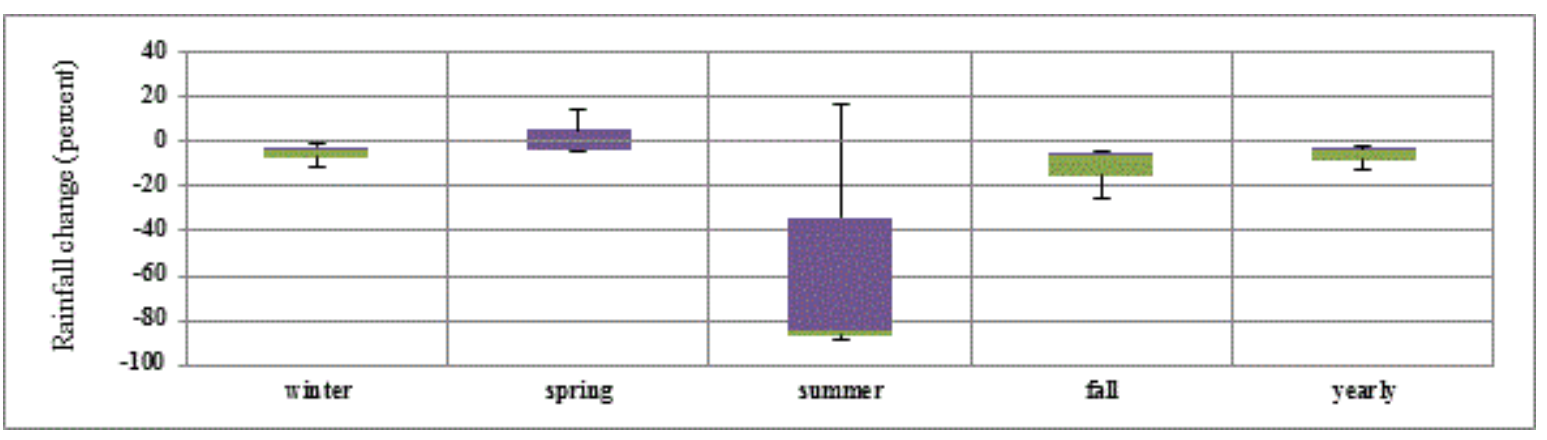

Figure 5: Boxplots showing uncertainty climate models (MPEH5 'HADCM3 and IPCM4) on seasonal rain fall Change under the A2 scenarios for the future periods 2045-2065 relative to reference periods 1983-1999. 
Citation: Nazari P, Kardavany H, Farajirad P, Abdolreza A (2016) Assessment of Runoff Changes under Climate Change Scenarios in the Dam Basin of Ekbatan, Hamedan Iran. J Climatol Weather Forecasting 4: 172. doi:10.4172/2332-2594.1000172

Page 5 of 10

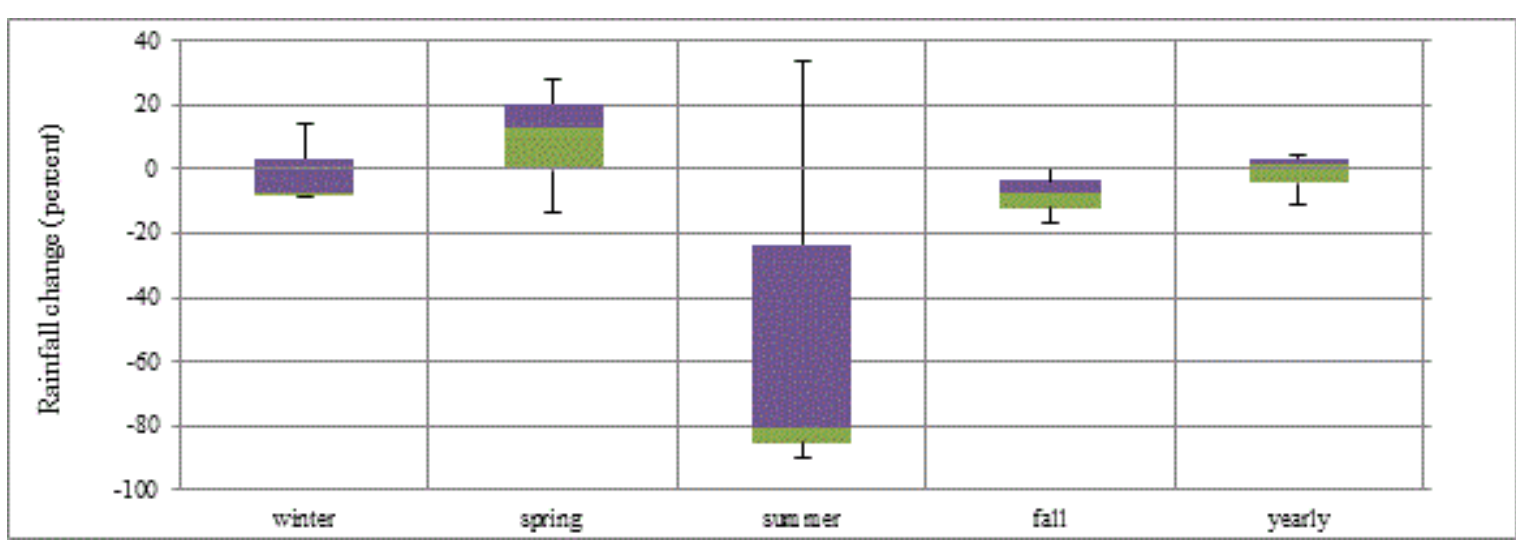

Figure 6: Boxplots showing uncertainty climate models (MPEH5 'HADCM3 and IPCM4) on seasonal rain fall Change under the B1 scenarios for the future periods 2045-2065 relative to reference periods 1983-1999.

\begin{tabular}{|c|c|c|c|c|c|c|c|c|c|c|c|c|}
\hline \multirow{2}{*}{ Season } & \multicolumn{6}{|l|}{ B1 } & \multicolumn{6}{|l|}{ A2 } \\
\hline & Min & Q1 & Median & Mean & Q3 & Max & Min & Q1 & Median & Mean & Q3 & Max \\
\hline Winter & -9 & -8.3 & -7.6 & -0.8 & 3.4 & 14.3 & -10.9 & -7.2 & -3.5 & -5 & -2.1 & -0.7 \\
\hline Spring & -13.3 & -0.3 & 12.6 & 9.2 & 20.4 & 28.2 & -4.6 & -4 & -3.4 & 2.3 & 5.7 & 14.7 \\
\hline Summer & -90.1 & -85.2 & -80.3 & -45.7 & -23.5 & 33.3 & -88.8 & -86.6 & -84.4 & -52.1 & -33.7 & 16.9 \\
\hline Fall & -17 & -12.1 & -7.2 & -8.1 & -3.6 & 0 & -24.8 & -15.2 & -5.7 & -11.4 & -4.8 & -3.9 \\
\hline
\end{tabular}

Table 1: Quartiles change in future (2045-2065) rainfall (\%) relative to 1983-2009 historical period for Sub basin for three GCM models and the A2, B1 emissions scenario.

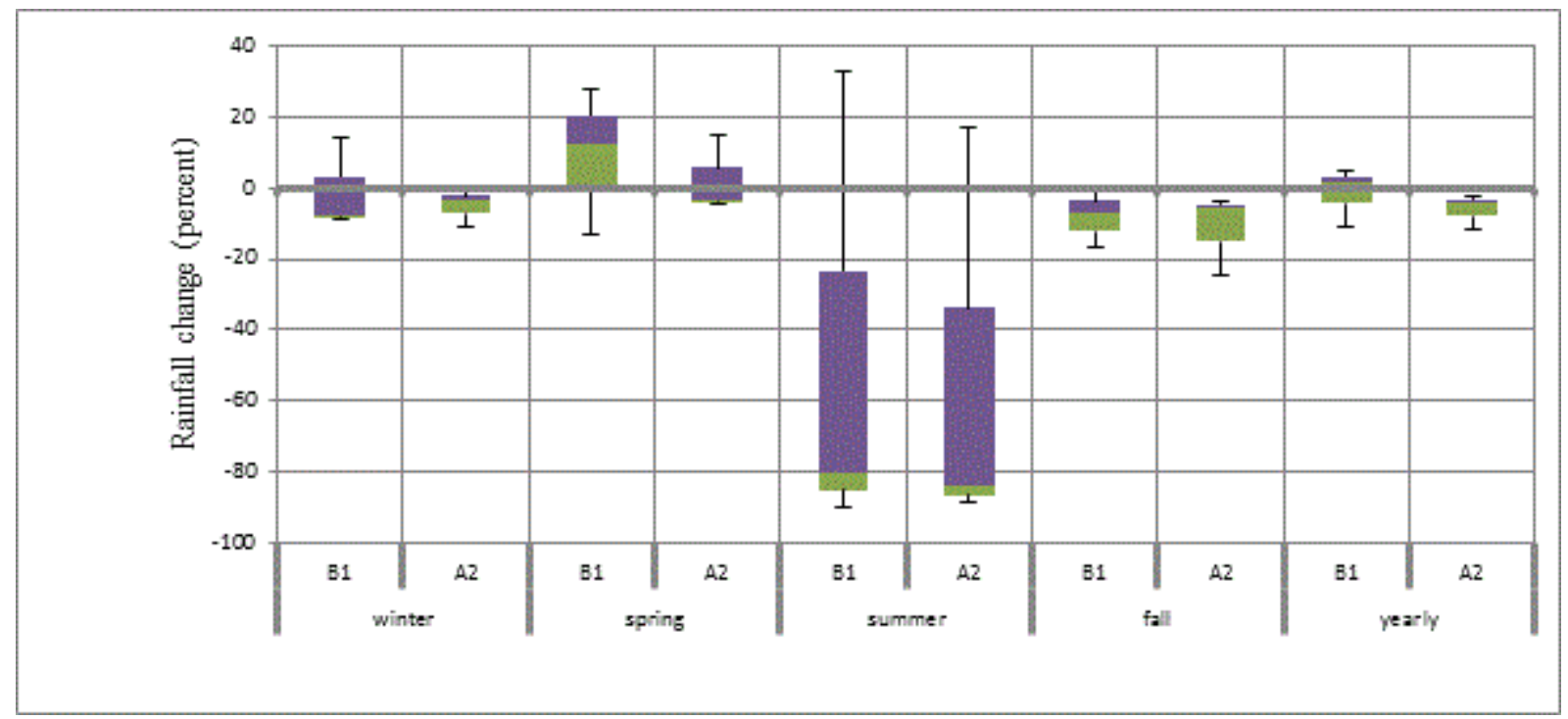

Figure 7: Boxplots comparing uncertainty climate models (MPEH5 'HADCM3 and IPCM4) on seasonal rainfall Change under the A2 and B1 scenarios for the future periods 2045-2065 relative to reference periods 1983-1999. 
Citation: $\quad$ Nazari P, Kardavany H, Farajirad P, Abdolreza A (2016) Assessment of Runoff Changes under Climate Change Scenarios in the Dam Basin of Ekbatan, Hamedan Iran. J Climatol Weather Forecasting 4: 172. doi:10.4172/2332-2594.1000172

Page 6 of 10

\section{Average temperatures}

Uncertainty of climate models under A2 and B1 for temperature estimate Show an increase in temperature of the region in the future. Survey results show that the seasonal average temperature under the scenario A2, increase $2.6^{\circ} \mathrm{C}$ and Under the Scenario B1, $2.2^{\circ} \mathrm{C}$ in summer. The average annual temperature will increase under two scenarios $\mathrm{A} 2$ and $\mathrm{B} 1$, respectively, $2.12^{\circ} \mathrm{C}$ and $1.79^{\circ} \mathrm{C}$.

During the period 2045-2065 the highest and lowest uncertainty average monthly temperature under two scenarios in the region are in May, June and July. The results showed that temperature changes coming in the future under the worst scenario A2, average monthly temperature will increase $2.92^{\circ} \mathrm{C}$ and the scenario $\mathrm{B} 1,2.51^{\circ} \mathrm{C}$ in July.
Due to the lower and upper limits of mean monthly temperature, according to the A2 scenario will increase $1.32^{\circ} \mathrm{C}$ in February to $3.44^{\circ} \mathrm{C}$ in July.

The highest and lowest average seasonal uncertainty in the region during the period 2045-2065 under the two scenarios is higher in spring than other seasons. Upper and lower limit average seasonal temperature changes in the region based on the scenario A2 varies from $1.54^{\circ} \mathrm{C}$ in winter to $2.96^{\circ} \mathrm{C}$ in summer and based on the $\mathrm{B} 1$ scenario varies from $2.21^{\circ} \mathrm{C}$ in autumn to $2.62^{\circ} \mathrm{C}$ in spring. Summer temperature increases are greater than for other seasons under the two emmision scenarious (Figures 8 and 9) (Table 2).

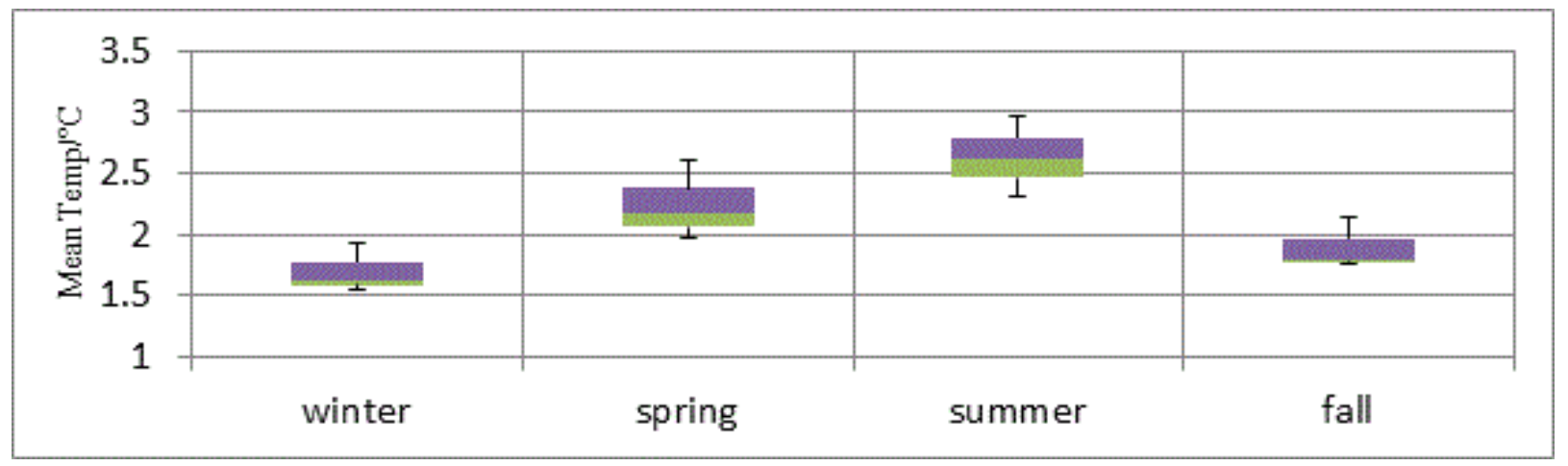

Figure 8: Boxplots showing uncertainty climate models (MPEH5 'HADCM3 and IPCM4) on seasonal Mean Temp Change under the A2 scenarios for the future periods 2045-2065 relative to reference periods 1983-1999.

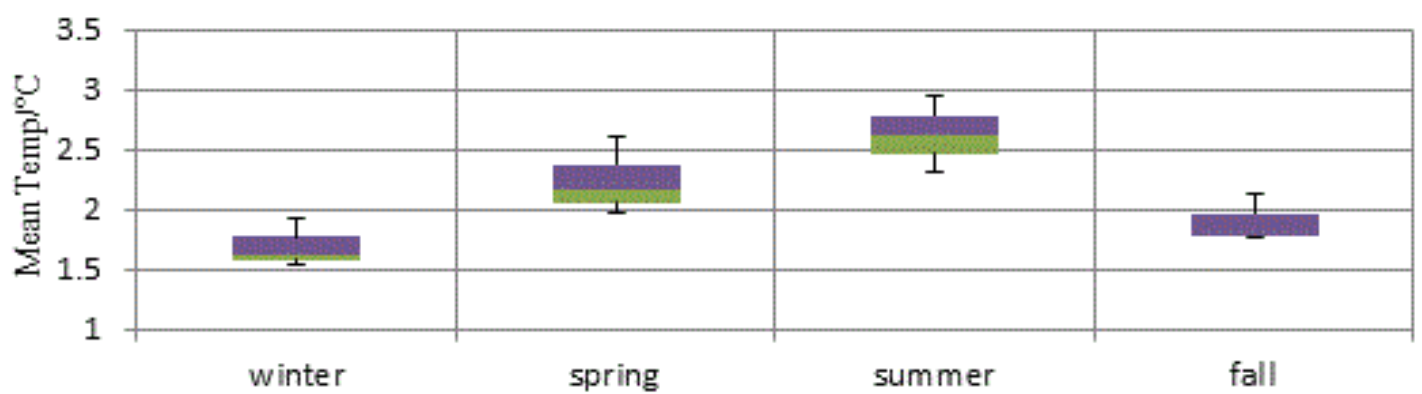

Figure 9: Boxplots showing uncertainty climate models (MPEH5 'HADCM3 and IPCM4) on seasonal Mean Temp Change under the B1 scenarios for the future periods 2045-2065 relative to reference periods 1983-1999.

\begin{tabular}{|c|c|c|c|c|c|c|c|c|c|c|c|c|}
\hline \multirow{2}{*}{ Season } & \multicolumn{6}{|l|}{ B1 } & \multicolumn{6}{|l|}{ A2 } \\
\hline & Min & Q1 & Median & Mean & Q3 & Max & Min & Q1 & Median & Mean & Q3 & Max \\
\hline Winter & 1.41 & 1.42 & 1.43 & 1.50 & 1.55 & 1.66 & 1.54 & 1.59 & 1.63 & 1.70 & 1.77 & 1.92 \\
\hline Spring & 1.79 & 1.84 & 1.88 & 2.10 & 2.25 & 2.62 & 1.97 & 2.06 & 2.16 & 2.24 & 2.38 & 2.61 \\
\hline
\end{tabular}


Citation: $\quad$ Nazari P, Kardavany H, Farajirad P, Abdolreza A (2016) Assessment of Runoff Changes under Climate Change Scenarios in the Dam Basin of Ekbatan, Hamedan Iran. J Climatol Weather Forecasting 4: 172. doi:10.4172/2332-2594.1000172

Page 7 of 10

\begin{tabular}{|l|l|l|l|l|l|l|l|l|l|l|l|l|}
\hline Summer & 1.97 & 2.06 & 2.15 & 2.16 & 2.26 & 2.37 & 2.32 & 2.47 & 2.62 & 2.63 & 2.79 & 2.96 \\
\hline Fall & 1.21 & 1.36 & 1.51 & 1.42 & 1.52 & 1.52 & 1.76 & 1.78 & 1.79 & 1.90 & 1.97 & 2.14 \\
\hline
\end{tabular}

Table 2: Quartiles change in future (2045-2065) Mean temp (\%) relative to 1983-2009 historical period for Sub basin for three GCM models and the $\mathrm{A} 2, \mathrm{~B} 1$ emissions scenario.

\section{Model Calibration and Validation}

The objective of calibration and validation was to maximizing the model efficiencies and finally using the parameter values obtained through those calibration techniques. This study uses IHACRES model. The calibration was performed using observed data from the year 1983-1999 period [14]. The calibrated model was validated using independent data 2000-2009, on monthly time step at Dam Basin of Ekbatan river gauge.

The time series plot of measured monthly runoff simulated during calibration period for best simulations are shown on Figures 3 and 4, respectively and the summarized objective function results are also shown on (Table 3). And to check the validity of the model, computed runoff have been compared with field observed flow data 1983-1999. The time series plot of measured monthly flow simulated during validation period are shown on Figures 5 and 6, respectively [15].

For determining the ability of the rainfall - runoff model to simulate runoff used Nash-Satcliffe coefficient. Results showed that IHACRES model suitable for the simulation runoff in the watershed. In Table 1 monthly Nash-Satcliffe factors are 0.68 for calibration period 1983-1999 and 0.72 validation period 2000-2009.

\begin{tabular}{|l|l|l|l|l|l|l|l|}
\hline $\begin{array}{l}\text { Sub } \\
\text { Basin }\end{array}$ & Operate & Period & $\mathrm{R}^{2}$ & $\begin{array}{l}\text { Nash- } \\
\text { Satcliffe }\end{array}$ & $\begin{array}{l}\text { Observe } \\
\mathrm{d}\end{array}$ & $\begin{array}{l}\text { Simulat } \\
\mathrm{e}\end{array}$ & $\mathrm{MAE}$ \\
\hline \multirow{3}{*}{ Yalfan } & $\begin{array}{l}\text { Calibratio } \\
\mathrm{n}\end{array}$ & $\begin{array}{l}1983-1 \\
999\end{array}$ & 0.68 & 0.68 & 1.4 & 1.43 & 0.69 \\
\cline { 2 - 8 } & Validation & $\begin{array}{l}2000-2 \\
009\end{array}$ & 0.72 & 0.72 & 1.17 & 1.14 & 0.54 \\
\hline
\end{tabular}

Table 3: Model performance evaluation coefficients for calibration and validation of Runoff.

The time series plot of measured monthly flow simulated during validation period are shown on Figure 9 and the summarized model predictive performance values are on Table 4 a quit good match is found during monthly time period. Thus, according to Nash coefficient can be concluded that the model is capable for runoff simulation and gives acceptable results in the study basin. In general, the modelled runoff agrees quite well with the observed data (Figure 10 and 11).

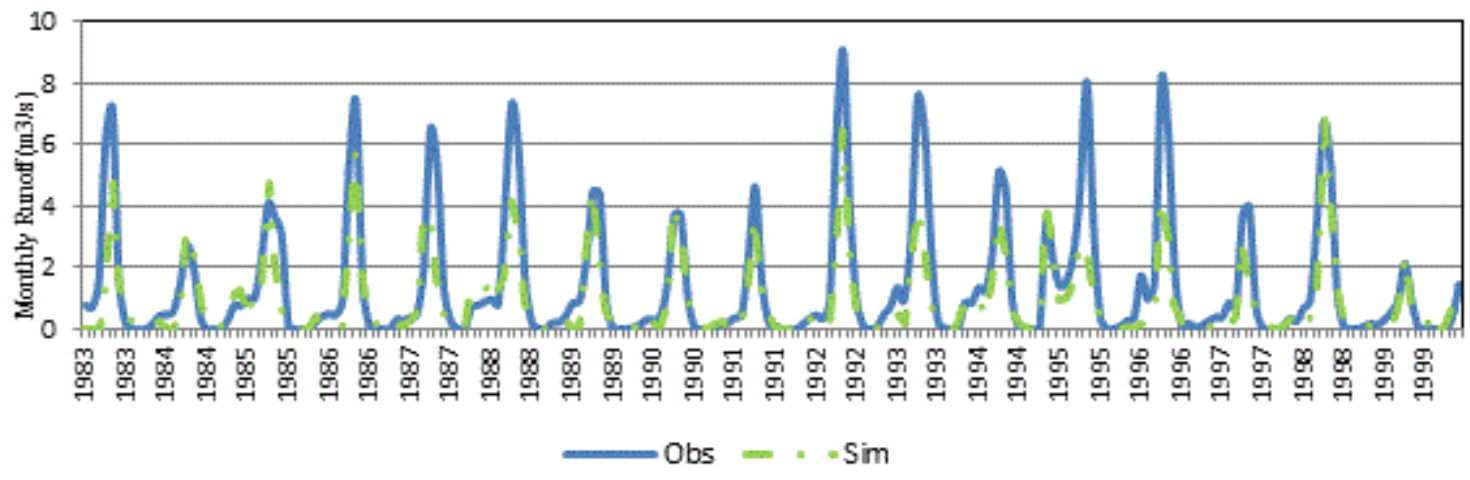

Figure 10: Observed and modelled stream flow for the calibration period (1983-1999). 
Citation: $\quad$ Nazari P, Kardavany H, Farajirad P, Abdolreza A (2016) Assessment of Runoff Changes under Climate Change Scenarios in the Dam Basin of Ekbatan, Hamedan Iran. J Climatol Weather Forecasting 4: 172. doi:10.4172/2332-2594.1000172

Page 8 of 10

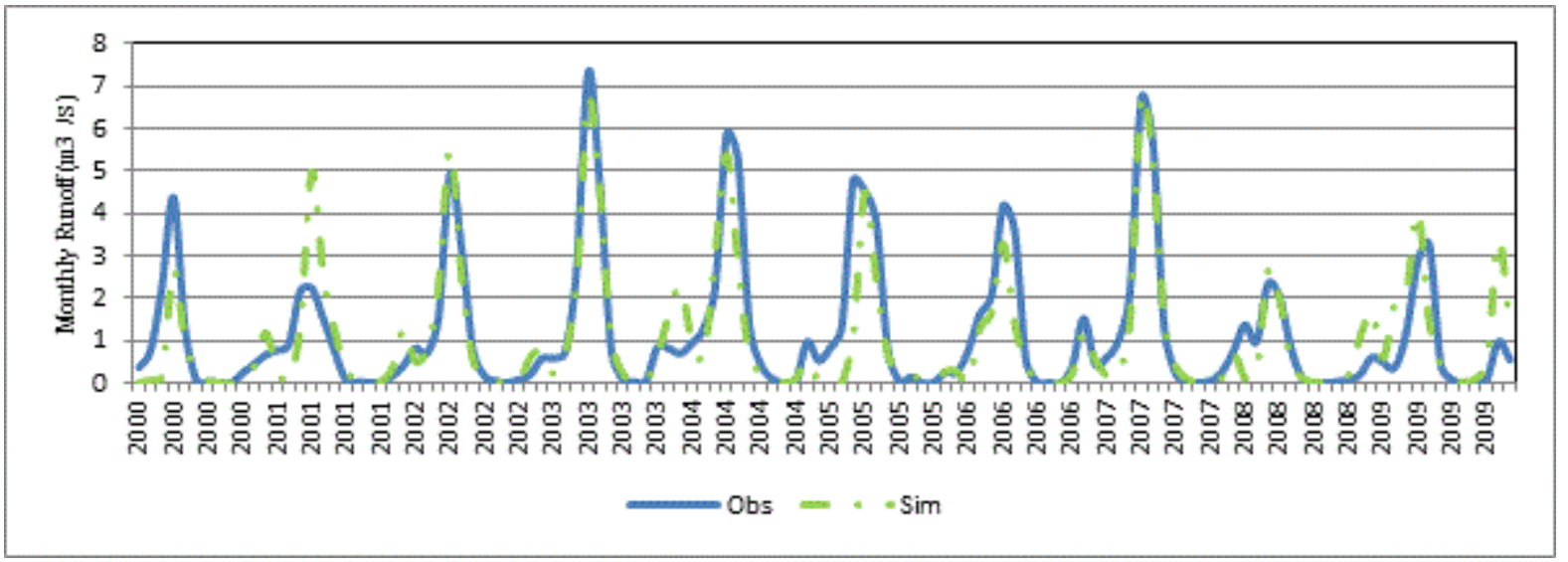

Figure 11: Observed and modelled stream flow for the validation period (2000-2009).

\section{Hydrologic impacts of climate change}

The impacts of climate change on hydrology at the catchment were quantified based on runoff simulated with the hydrological model IHACRES.

The results and the estimation of surface runoff basin provided using model IHACRES according to climate models HADCM3, IPCM and MPEH5 under climate change scenarios A2 and B1 in Figure 3 and Table 2 for 2045-2065 period. The results show that there are great uncertainty in the estimation of runoff, according to climate models HADCM3, IPCM and MPEH5 under climate change scenarios A2 and B1. According to Figures 12 and 13 graphs show the greatest uncertainties in summer and autumn and the least uncertainty in winter. The results showed that Based on the Figure14 and Table 4 runoff decreases in most months of the year according to most climate models in the basin. The climate models predict decreases in fall, summer spring seasons flows exception winter. Consequently with larger increase in winter temperatures the liquid winter precipitation rapidly contributes to runoff instead of being accumulated in the snow cover. Thus, there is not very much snowmelt in spring to contribute to peak discharge.

According to climate models HADCM3, IPCM, MPE5 under climate change $\mathrm{A} 2$ and $\mathrm{B} 1$ scenarios increases the amount of runoff in the basin during the winter season. The average annual runoff will be reduced according to climate models. Percentage runoff changes based on climate models and emission scenarios A2 and B1 are shown in Table 4. Winter runoff increases under the tow emission scenarios. The mean annual runoff is expected to reduce by $17.2 \%$ and $19.4 \%$ in 2045-2065 period for the A2 and B1 scenarios, respectively relative to base period.

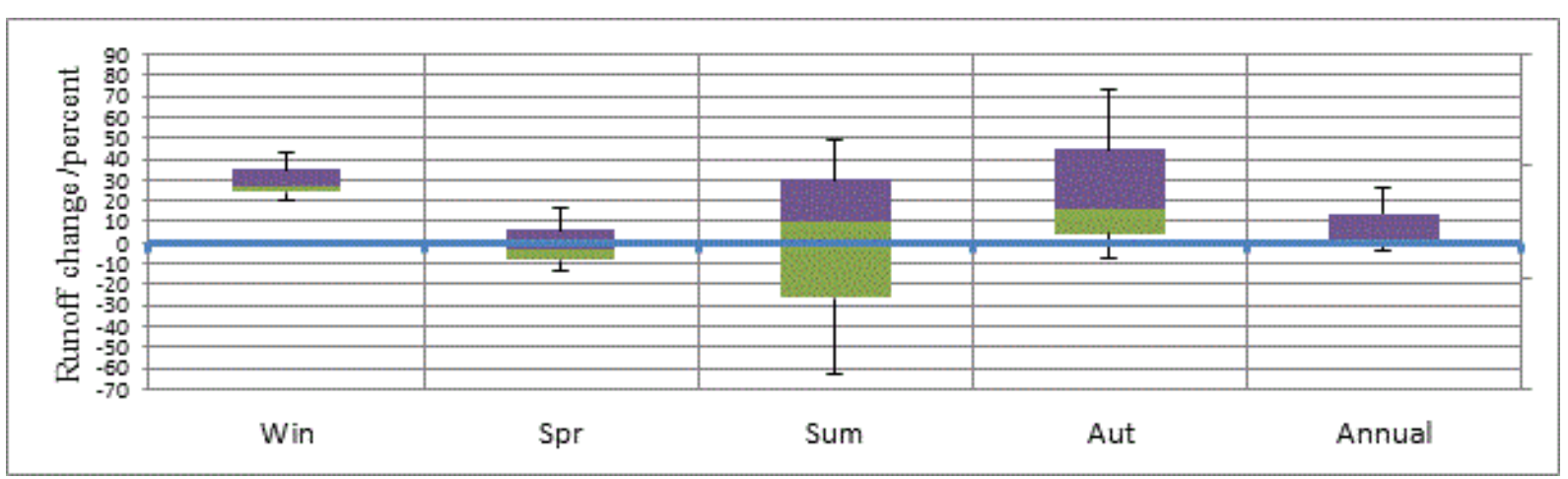

Figure 12: Uncertainty in climate models under the emissions scenario A2 for Runoff change in 2045-2065 period relative to base $1983-2009$ period. 
Citation: $\quad$ Nazari P, Kardavany H, Farajirad P, Abdolreza A (2016) Assessment of Runoff Changes under Climate Change Scenarios in the Dam Basin of Ekbatan, Hamedan Iran. J Climatol Weather Forecasting 4: 172. doi:10.4172/2332-2594.1000172

Page 9 of 10

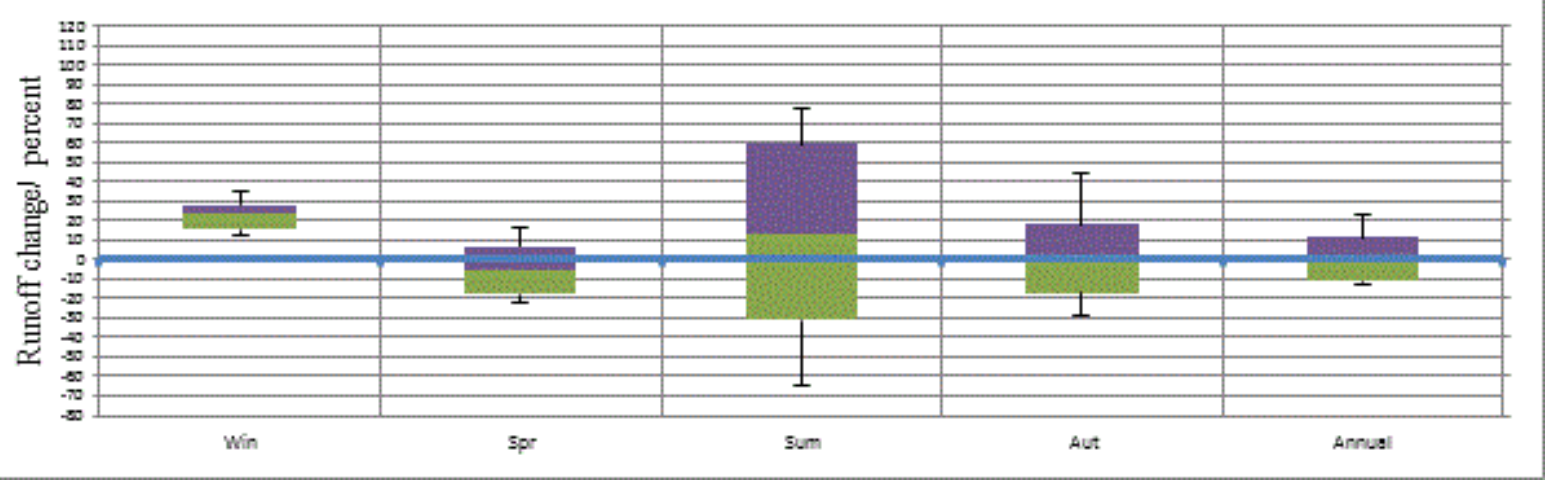

Figure 13: Relative uncertainty in climate models under the emissions scenario B1 for Runoff change in 2045-2065 period relative to base 1983-2009 period.

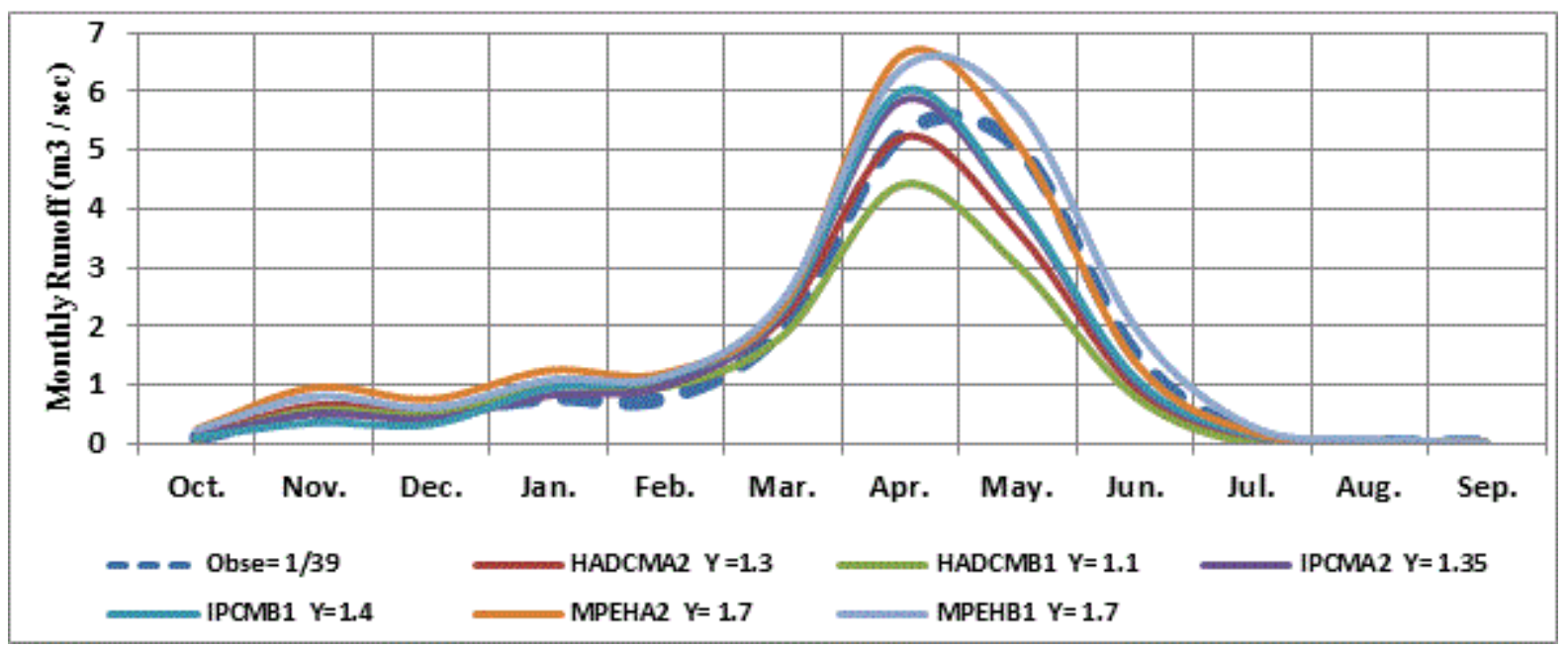

Figure 14: Monthly runoff hydrographs, 2050s time horizon for climate models under the A2 and B1 emissions scenarious.

\begin{tabular}{|l|l|l|l|l|l|l|}
\hline Season & HADCA2 & HADCB1 & IPCMA2 & IPCMB1 & MPEHA2 & MPEHB1 \\
\hline Winter & -4.9 & 22.1 & 22.7 & 23.2 & 69.4 & 46 \\
\hline Spring & -23.6 & -49.4 & -35.1 & -29.7 & -31.8 & -17.1 \\
\hline Summer & -38.8 & -70.5 & -53.7 & -30.7 & -44.3 & 40.3 \\
\hline Fall & -43 & -34.9 & -53.7 & -75.3 & 31.3 & -15 \\
\hline Yearly & -21.2 & -33.5 & -24.4 & -21.8 & -6 & -3 \\
\hline
\end{tabular}

The effects of climate change, changes in temperature, precipitation and runoff area. For assessing the impact of climate change on climate parameters and runoff, there are various uncertainties which include downscaling techniques, climate models and climate scenarios. According to assessing the impact of climate change on water resources for various uncertainties affect the final results and to ignore any of them do not have the final results ensure. So for this reason, the uncertainty of climate models IPCM4, MPEH5, HADCM3 and A2, B1 scenario for the period 2045-2065 were calculated for the studied area [16]. Review monthly rainfall during the period 2045-2065 in the area showed that under the $\mathrm{A} 2$ scenario the greatest reduction in rainfall will happen $-45.3 \%$ in October $(-10.8 \mathrm{~mm})$ and under the B1 scenario $-3.5 \%$ in October $(-8.2 \mathrm{~mm})$. Evaluation of seasonal rainfall in the same period in the designated area showed that the most significant reduction in the A2 scenario $-11.4 \%$ in the fall $(-13.1 \mathrm{~mm})$ and according to the B1 scenario, -8.1 percent in the fall $(-104 \mathrm{~mm})$. Annual precipitation decrease in the A2 scenario $-6.1 \%(-12.2 \mathrm{~mm})$ and according to the $\mathrm{B} 1$ scenario $-1.4 \%(-0.5 \mathrm{~mm})$.

The results of the seasonal average temperature over the period 2045-2065 showed that, under the scenario A2, average monthly 
Citation: $\quad$ Nazari P, Kardavany H, Farajirad P, Abdolreza A (2016) Assessment of Runoff Changes under Climate Change Scenarios in the Dam Basin of Ekbatan, Hamedan Iran. J Climatol Weather Forecasting 4: 172. doi:10.4172/2332-2594.1000172

Page 10 of 10

temperature increase $2.6^{\circ} \mathrm{C}$ in summer and under the the scenario $\mathrm{B} 1$, $16 / 2$ in summer and the average annual temperature increased under the tow emission scenarious A2, B1 $2.12^{\circ} \mathrm{C}$ and $1.79^{\circ} \mathrm{C}$, respectively.

The results of the hydrological model simulations and estimates suggest that in the coming period, the monthly runoff hydrograph in the study basin will be changed compared to the baseline and shows move towards the winter and will be shift peak runoff in the winter (left).

On the other hand predicted hydrologic responses increased winter runoff special March and decreased fall, spring and summer. The shift in seasonal runoff has been attributed to warmer air temperatures forcing greater rain precipitation compared to snow precipitation. Subsequently less winter snow precipitation results in decreased snow melt runoff in the spring and subsequently lower base flow in summer. This shift caused by increased river flow in March and reduce in the spring. March runoff increases caused by rising temperatures and changing precipitation from snow to rain in the winter and early melting snow in the upper basin reservoirs in mountainous areas. The results of this study show that ignore climate model uncertainty huge impact on runoff and precipitation basin will be affected by climate.

Proportional to the increase in average temperature between 1.4 to $2.9^{\circ} \mathrm{C}$ in most months will increase evapotranspiration and Crop water requirement in the region. Therefore, it is essential to plan for the proper management of water resources by altering the pattern of plants and should be considered modification of cropping patterns and irrigation methods to adapt and mitigate the effects of climate change.

\section{References}

1. IPCC (2007) Summary for Policymarkers in: Climate Change 2007, Climate Compatibility Comprehensive Program. The Grand Karun Watershed 1.

2. Chang H, Jung IW (2010) Spatial and temporal changes in runoff caused by climate change in a complex large river basin in Oregon. J Hydr 388: 186-207.

3. Ye W, Bates BC, Viney NR, Sivapalan M, Jakeman AJ (1997) Performance of conceptual rainfall-runoff models in low-yielding ephemeral catchments. Water Res 33: 153-166.
4. Zarghami M, Abdi A, Babaeian I, Hassanzadeh Y, Kanani R (2011) Impacts of climate change on run off sin East Azerbaijan, Iran. Global and Planetary Change 78: 137-146.

5. Jakeman AJ, Hornberger GM (1993) How much complexity is warranted in a rainfall - runoff model? Water Resources Research 29: 2637-2649.

6. Nakicenovic N, Alcamo J, Davis G, de Vries B, Fenhann J, et al. (2000) Special Report on Emissions Scenarios: A Special Report of Working Group III of the Inter governmental Panel on Climate Change. New York: Cambridge University Press.

7. Foley AM (2010) Uncertainty in regional climate modelling. Progress in Physical Geography 34: 647-670.

8. Gershon ND (1998) Visualization of an imperfect world. Computer Graphics and Applications 18: 43-45.

9. Hulme M, Carter TR (1999) Representing uncertainty in climate change scenarios and impact studies. In: Carter TR, Hulme M, and Viner D (eds) Representing Uncertainty in Climate Change Scenarios and Impact Studies. ECLAT-2 Report No 1, Helsinki Workshop, 14-16.

10. Massah Bovani A (2006) Evaluation of Climate Change Risk and its Effect on Water Resources, Case Study: Zayandeh Roud, Isfahan, Ph.D. Final Thesis Report, Water EngineeringResearch Center, Tarbiat Modares University, Tehran.

11. Pruski FF, Nearing MA (2002) Runoff and soil-loss responses to changes in precipitation: A computer simulation study. J Soil and Water Cons 57: 7-6.

12. Gosain A, Rao S, Basuray D (2006) Climate change impact assessment on hydrology of Indian river basins. Current Science 90: 346-353.

13. Hamlet AF, Lettenmaier DP (2007) Effects of 20th century warming and climate variability on flood risk in the western U.S. Water Resour 43: W06427.

14. Senatore A, Mendicino G, Smiatek G, Kunstmann H (2011) J Hydr 339: 70-92.

15. Littlewood IG (2002) Improved unit hydrograph characterisation of the daily flow regime (including low flows) for the River Teifi, Wales: towards better rainfall-streamflow models for regionalisation. Hydrology and Earth System Sciences 6: 899-911.

16. Croke BFW, Jakeman AJ (2004) A catchment moisture deficit module for the IHACRES rainfall-runoff model. Environmental Modelling \& Software 19: 1-5. 